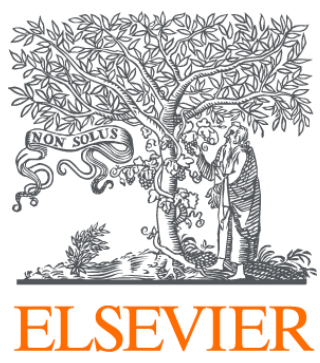

Since January 2020 Elsevier has created a COVID-19 resource centre with free information in English and Mandarin on the novel coronavirus COVID-

19. The COVID-19 resource centre is hosted on Elsevier Connect, the company's public news and information website.

Elsevier hereby grants permission to make all its COVID-19-related research that is available on the COVID-19 resource centre - including this research content - immediately available in PubMed Central and other publicly funded repositories, such as the WHO COVID database with rights for unrestricted research re-use and analyses in any form or by any means with acknowledgement of the original source. These permissions are granted for free by Elsevier for as long as the COVID-19 resource centre remains active. 
Full length article

\title{
Food phytochemicals, epigallocatechin gallate and myricetin, covalently bind to the active site of the coronavirus main protease in vitro
}

\author{
Yoji Kato $^{\mathrm{a}, \mathrm{b}, *}$, Akari Higashiyama ${ }^{\mathrm{a}}$, Emi Takaoka $^{\mathrm{a}}$, Miyu Nishikawa ${ }^{\mathrm{c}}$, Shinichi Ikushiro ${ }^{\mathrm{c}}$ \\ ${ }^{a}$ School of Human Science and Environment \\ ${ }^{\mathrm{b}}$ Research Institute for Food and Nutritional Sciences, University of Hyogo, Himeji, Hyogo, 670-0092, Japan \\ c Department of Biotechnology, Faculty of Engineering, Toyama Prefectural University, Imizu, Toyama, 939-0398, Japan
}

\section{A R T I C L E I N F O}

\section{Keywords:}

Coronavirus main protease

Food phytochemical

EGCG

Myricetin

Autoxidation

Covalent modification

\begin{abstract}
A B S T R A C T
SARS-CoV-2 main protease is a possible target for protection against viral infection. This study examined the inhibitory effect of food phytochemicals on the main protease of SARS-CoV-2 by determining a cleaved product after chromatographic separation. First, 37 phytochemicals, including glycosides and metabolites, were screened at $20 \mu \mathrm{M}$; epigallocatechin gallate, myricetin, theaflavin, herbacetin, piceatannol, myricitrin, and isothiocyanates inhibited the enzyme in varying degrees. The $\mathrm{IC}_{50}$ values were estimated from 0.4 to $33.3 \mu \mathrm{M}$ against the 0.5 $\mu \mathrm{M}$ enzyme. The dose-dependent adduction of epigallocatechin gallate and myricetin was confirmed by quinone staining of protein blotted onto a membrane. The enzyme activity was decreased by increasing the concentration of the two phytochemicals, accompanied by increasing the respective adducted molecule estimated by intact mass spectrometry. Reduced glutathione canceled the formation of conjugate and the inhibitory effect of epigallocatechin gallate or myricetin on the enzyme, suggesting that the formation of the quinone moiety in the phytochemicals is critical for the inhibition. The covalent binding of epigallocatechin gallate or myricetin to the cysteine residue at the active site was confirmed by analyzing peptides from the chymotrypsin-digested main protease.
\end{abstract}

\section{Introduction}

Coronavirus disease 2019 (COVID-19) caused by SARS-CoV-2 has rapidly spread globally and threatens human life. There are some promising target molecules to prevent the virus infection or proliferation. This study focuses on the coronavirus main protease $\left(\mathrm{M}^{\text {pro }}\right.$, alternatively 3C-like protease), which mediates the scission of viral protein to replicate. The $\mathrm{M}^{\text {pro }}$ protease inhibitor, GC376, reduced the viral titer in cats with feline infectious peritonitis virus from feline enteric coronavirus [1]. Also, a similar peptidergic $\mathrm{M}^{\text {pro }}$ inhibitor improved the survival of mice infected by MERS-CoV [2]. Judging from the similarity among the coronavirus family, the SARS-CoV-2 $\mathrm{M}^{\text {pro }}$ is a promising target for preventing COVID-19. After reports about the crystal structure of $\mathrm{M}^{\text {pro }}$ from SARS-CoV-2 with an inhibitor [3,4], many attempts to evaluate inhibitors, including natural chemicals, have proceeded in in silico study.

Food is a good source for health promotion; it can supply beneficial phytochemicals to humans. Thus, the daily consumption of phytochemicals could help strengthen our body against diseases, such as COVID-19. Formerly, experimental studies for the inhibitory effect of flavonoids on the recombinant protease from SARS-CoV-1 (classic) or MERS-CoV have been reported; some flavonoids, including herbacetin and quercetin 3O-glucoside, inhibited MERS-CoV Mpro [5]. SARS-CoV-1 Mpro was inhibited by flavonoids and flavones, such as herbacetin, rhoifolin, pectolinarin, apigenin, luteolin, quercetin, and amentoflavone [6,7]. Concerning SARS-CoV-2 $\mathrm{M}^{\text {pro }}$, epigallocatechin gallate (EGCG) [8,9], theaflavin [8], myricetin [10], quercetin [11], herbacetin, pectolinarin, baicalin [12], rutin, baicalein [13], and cyanidin-3-glucoside [14] shows inhibitory effects on the enzyme in vitro. Most research was performed by fluorescence resonance energy transfer (FRET) assay, which sometimes results in false negatives or positives due to the interference of fluorescence signals derived from test chemicals [15]; a competitive binding assay using the fluorescent probe 8-anilinonaphthalene-1-sulfonate is also reported [13].

The study examines the inhibitory effect of food phytochemicals by directly measuring the digested peptide substrate after highperformance liquid chromatography (HPLC) separation. Additionally, the mechanism of inhibition by covalent adduction of phytochemicals, such as EGCG and myricetin, was estimated by quinone staining and mass spectrometry (MS).

\footnotetext{
* Corresponding author at: School of Human Science and Environment, University of Hyogo, Hyogo 670-0092, Japan

E-mail address: yojikato@shse.u-hyogo.ac.jp (Y. Kato).
} 


\section{Materials and methods}

\section{Materials}

Dabcyl-KTSAVLQSGFRKME-Edans was purchased from GL Biochem, Ltd. (Shanghai, China). GC376 and herbacetin were obtained from Cayman Chemical (MI, USA). Kaempferol, quercetin, theaflavin, isoquercetin (quercetin-3-O-glucoside), cyanidine chloride, and nitroblue tetrazolium (NBT) were from Fujifilm-Wako Pure Chemical Co. (Osaka, Japan). Pectolinarin was purchased from Merck Sigma-Aldrich (MA, USA). Cyanidine-3-glucoside chloride, cyanidine-3-rutinoside chloride, and luteolin-7-O-glucoside were obtained from Extrasynthese S.A. (Lyon, France). Cyanidine-3-sophoroside chloride and cyanidine-3-Oglucosyl-rutinoside (C-3-GR) chloride were from Tokiwa Phytochemical Co., Ltd. (Chiba, Japan). Allyl isothiocyanate (AITC), benzyl isothiocyanate (BITC), phenethyl isothiocyanate (PEITC), ebselen, resveratrol, luteolin, isorhamnetin (IR), baicalein, myricitrin, piceatannol, rhapontigenin, and isorhapontigenin were obtained from Tokyo Chemical Industry Co., Ltd. (Tokyo, Japan). Luteolin-7-O-glucuronide was from MedChemExpress (NJ, USA). Rutin (quercetin-3-O-rutinoside) was purchased from Nacalai Tesque, Inc. (Kyoto, Japan). EGCG was purchased from LKT Labs, Inc. (MN, USA). Quercetin-7-O-glucuroinde, quercetin-3-O-glucuroinde, quercetin-4'-O-glucuroinde, quercetin3'-O-glucuroinde, isorhamnetin-7-O-glucuronide, isorhamnetin-3-Oglucuronide, isorhamnetin-4'-O-glucuronide, quercetin-7-O-sulfate, quercetin-3'-O-sulfate, and quercetin-4'-O-sulfate were prepared as described previously $[16,17]$. Chymotrypsin (sequencing grade) and ProteaseMAX were purchased from Promega (WI, USA). Amylose resin and Factor Xa were obtained from New England Biolabs Japan Inc. (Tokyo, Japan). Other chemicals used were of high-quality grades, unless otherwise indicated.

Preparation of maltose-binding protein (MBP)-tagged main protease and its MBP-cleaved protease

The MBP-tagged main protease containing SARS-CoV-2 Mpro (GenBank Accession No. YP_009725301; Met1-Gln306) was constructed using pMAL-c2 expression vector (New England Biolabs Japan Inc.). The gene encoding SARS-CoV-2 $\mathrm{M}^{\text {pro }}$ with $E$. coli codon usage was synthesized by Eurofins Genomics (Tokyo, Japan). The fusion protein was purified by amylose-conjugated affinity chromatography. MBP-cleaved $\mathrm{M}^{\text {pro }}$ was prepared from MBP-tagged $\mathrm{M}^{\text {pro }}$ by Factor Xa protease digestion. The prepared $\mathrm{M}^{\text {pro }}$ showed a single band (MBP-tagged Mpro, $77.5 \mathrm{kDa}$; MBP-cleaved $\mathrm{M}^{\text {pro }}, 34.7 \mathrm{kDa}$ ) (Supplemental Fig. 1). The concentration of each protein was estimated by bicinchoninic acid protein assay.

\section{Measurement of enzyme activity by HPLC fluorescence detection}

The enzymatic reaction was performed in a $20-\mathrm{mM}$ Tris- $\mathrm{HCl}$ buffer containing 1-mM ethylenediaminetetraacetic acid (EDTA), 150-mM $\mathrm{NaCl}$, and $0.01 \%$ Triton $\mathrm{X}-100 \mathrm{(pH} 7.5)$. All tested chemicals were dissolved in dimethyl sulfoxide (DMSO), and the concentration of DMSO was $2 \%$ in the reaction mixture, unless otherwise indicated. The enzyme protease $(0.5 \mu \mathrm{M})$ was preincubated with an inhibitor $(0-200 \mu \mathrm{M})$ or vehicle at $37^{\circ} \mathrm{C}$ for $30 \mathrm{~min}$, unless otherwise indicated. After that, $10-\mu \mathrm{M}$ Dabcyl-KTSAVLQSGFRKME-Edans was added to the solution and further incubated for $1 \mathrm{~h}$. The reaction was terminated by adding an equal volume of $\mathrm{CH}_{3} \mathrm{CN}$ containing $0.1 \%$ formic acid, and $10 \mu \mathrm{L}$ of the mixture was injected into the Shimadzu Prominence HPLC connected with a photodiode array detector (PDA) and an RF-10XL fluorescence detector (ex. $336 \mathrm{~nm}$, em. $490 \mathrm{~nm}$ ) in series (Shimadzu Co., Kyoto, Japan). PDA was used to check possible co-elution with the fluorescent peptide and an additive. The fluorescence detector was used to quantify cleaved fluoresce peptide. The separation was done using a Phenomenex Kinetex XB-C18 $(4.6 \times 50 \mathrm{~mm}, 2.6 \mu \mathrm{m})$ with gradient elution using $0.1 \%$ trifluoroacetic acid in water (solvent $\mathrm{A}$ ) and $\mathrm{CH}_{3} \mathrm{CN}$ (solvent $\mathrm{B}$ ) at a flow rate of $1.0 \mathrm{~mL} / \mathrm{min}$. The gradient program was as follows: initial B10\%, $3 \mathrm{~min}$ $\mathrm{B} 100 \%, 4 \mathrm{~min} \mathrm{~B} 10 \%$, and $10 \mathrm{~min} \mathrm{~B} 10 \%$. The analysis was performed in triplicate. The $\mathrm{IC}_{50}$ value was calculated using Prism v.9.2 (GraphPad Software, LLC., CA, USA).

The scission products were confirmed using a quadrupole-time-offlight mass spectrometer [Q-TOF, X500R, Sciex (MA, USA)] connected with ultra-high-performance liquid chromatography (UHPLC, Exion, Sciex). After the reaction, the reaction mixture was then separated using a Thermo Scientific Hypersil Gold column $(2.1 \times 100 \mathrm{~mm}, 1.9 \mu \mathrm{m})$ by gradient elution using $0.1 \%$ formic acid in water (solvent $\mathrm{A}$ ) and $\mathrm{CH}_{3} \mathrm{CN}$ (solvent $\mathrm{B}$ ) at a flow rate of $0.4 \mathrm{~mL} / \mathrm{min}$. The gradient program was as follows: initial B10\%, 2 min B100\%, $2.1 \mathrm{~min} \mathrm{~B} 10 \%$, and 4 min $\mathrm{B} 10 \%$. Finally, the eluate was introduced into the Q-TOF mass spectrometer and analyzed using information-dependent analysis mode.

\section{Intact $M S$ and deconvolution of the MS spectrum}

The MBP-cleaved enzyme $(0.5 \mu \mathrm{M})$ was incubated with a test chemical (0-5 $\mu \mathrm{M}$, typically $1 \mu \mathrm{M})$ in Tris-HCl buffer as shown above for 30 min at $37^{\circ} \mathrm{C}$. The protein $(10 \mu \mathrm{L})$ was separated using a Phenomenex bioZen Intact XB-C8 column $(2.1 \times 100 \mathrm{~mm}, 3.6 \mu \mathrm{m})$ for gradient elution using $0.1 \%$ formic acid in water (solvent $\mathrm{A}$ ) and $0.1 \%$ formic acid in $\mathrm{CH}_{3} \mathrm{CN}$ (solvent B) at a flow rate of $0.3 \mathrm{~mL} / \mathrm{min}$ connected to the MS. The gradient program was as follows: initial B5\%, $0.5 \mathrm{~min}$ B5\%, $4 \mathrm{~min} \mathrm{B90 \% ,} 5 \mathrm{~min}$ B5\%, and 8 min B5\%. The eluate was introduced into the MS using TOF-positive mode. This experiment was performed twice. The deconvolution of the mass spectrum was acquired by UniDec (v.4.4.1) [18].

Detection of quinones on the blotted membrane by redox-cycling staining

After incubating the enzyme with the test chemical, 10-mM dithiothreitol and $\times 4$ Laemmli sample loading buffer (Bio-Rad, CA, USA) were added to the reaction mixture. The sample (60-ng protein/lane) and Precision Plus Protein Dual Color Standard (Bio-Rad) were then applied to an SDS-polyacrylamide gel (SDS-PAGE, 10\% acrylamide) and then migrated by electrophoresis. The proteins in gels were blotted onto a PVDF membrane (Immobilon-P, Merck), and quinones on the membrane were stained using NBT (0.24 mM) in 2-M glycine- $\mathrm{NaOH}$ ( $\mathrm{pH} 10)$ as described previously $[19,20]$. The same samples were separated using a gel, and the proteins in the gel were stained using Flamingo Stain (Bio-Rad) according to the manufactures' protocol. Detection was performed using a LAS1000 plus (Fujifilm, Tokyo, Japan). This experiment was performed twice.

\section{Estimation of free thiols by biotin incorporation into the protein}

Detection of free thiols in the enzyme was performed as described previously with some modifications [20]. First, protein samples were incubated with 0.25 -mM EZ-link iodoacetyl-LC-biotin (Thermo Scientific, IL, USA) for $30 \mathrm{~min}$ in the dark and then mixed with $10-\mathrm{mM}$ of dithiothreitol and the $\times 4$ loading buffer. Next, the sample (20-ng protein/lane) was separated by $10 \%$ SDS-PAGE and the gels were blotted onto a PVDF membrane; the membrane was then blocked by EzBlock Chemi (ATTO Co., Tokyo, Japan) for $30 \mathrm{~min}$. Finally, the membrane was treated with streptavidin-peroxidase polymer (Merck, ultrasensitive, 1/100,000) for $30 \mathrm{~min}$, and the binding was visualized by ChemiLumi One L (Nacalai Tesque, Inc.). This experiment was performed twice.

\section{Identification of an adducted site in $M^{\text {pro }}$ by digestion with chymotrypsin}

The MBP-cleaved enzyme $(5 \mu \mathrm{M})$ was incubated with EGCG/myricetin $(10 \mu \mathrm{M})$ in the Tris- $\mathrm{HCl}$ buffer at $37^{\circ} \mathrm{C}$ for 30 min. The reaction mixture $(50 \mu \mathrm{L})$ was then applied to a tube for centrifugal ultrafiltration (Amicon Ultra 10K, Merck). Then, 450- $\mu \mathrm{L}$ 0.1-M Tris- $\mathrm{HCl}$ containing $10-\mathrm{mM} \mathrm{CaCl}_{2}$ (pH 8.0) was added and centrifuged to exchange the buffer for digestion. To the protein fraction, $100-\mu \mathrm{L}$ chymotrypsin $(1.7 \mu \mathrm{g})$ in buffer containing $0.025 \%$ ProteaseMAX was added and then further incubated at $25^{\circ} \mathrm{C}$ for $6 \mathrm{~h}$. The digested sample was purified using a peptide desalting and enrichment Tip, GL-Tip SDB (GL Sciences Inc., Tokyo, Japan) according to the manufacturers' 
protocol. Peptide separation was done using a Phenomenex Jupiter PROTEO C18 column $(2 \times 150 \mathrm{~mm}, 5 \mu \mathrm{m})$ with a gradient elution system at $0.2 \mathrm{ml} / \mathrm{min}$ flow rate. Solvent A was $0.1 \%$ formic acid in $\mathrm{H}_{2} \mathrm{O}$, and solvent $\mathrm{B}$ was $0.1 \%$ formic acid in $\mathrm{CH}_{3} \mathrm{CN}$. The linear gradient program was as follows: initial B2\%, 4 min B2\%, $55 \mathrm{~min} \mathrm{~B} 40 \%, 58 \mathrm{~min}$ B90\%, 59 min B90\%, 60 min B2\%, and 75 min B2\%. The eluate was introduced into the MS with positive mode. MS-Digest, ProteinSpector (https://prospector.ucsf.edu/prospector/mshome.htm) was used to calculate the theoretical mass numbers of modified peptides. This experiment was performed three times, and the typical result was shown.

\section{Results}

To examine the inhibitory effect of 37 phytochemicals on $\mathrm{M}^{\text {pro }}$ (MBP-tagged $\mathrm{M}^{\text {pro }}$ ), Dabcyl-KTSAVLQSGFRKME-Edans was used as a substrate, and the formed cleaved peptide (SGFRKME-Edans) was then estimated using an HPLC fluorescence detector. Before the screening, the generation of cleaved peptides (Dabcyl-KTSAVLQ and SGFRKMEEdans), as products, was confirmed by TOF-MS. The scission fragment molecule of Dabcyl-KTSAVLQ has $\mathrm{C}_{47} \mathrm{H}_{72} \mathrm{~N}_{12} \mathrm{O}_{12}\left([\mathrm{M}+\mathrm{H}]^{+}\right.$996.54), and the other fragment of SGFRKME-Edans has $\mathrm{C}_{48} \mathrm{H}_{71} \mathrm{~N}_{13} \mathrm{O}_{13} \mathrm{~S}_{2}\left([\mathrm{M}+\mathrm{H}]^{+}\right.$ 1101.47).

At $20 \mu \mathrm{M}$, several phytochemicals had a considerable suppressive effect on the protease activity of the enzyme $(0.5 \mu \mathrm{M})(\mathrm{Fig}$. $1 \mathrm{~A})$. The $\mathrm{IC}_{50} \mathrm{~S}$ for the phytochemicals were estimated as EGCG $(0.4 \mu \mathrm{M})$, myricetin $(0.9$ $\mu \mathrm{M})$, theaflavin $(6.1 \mu \mathrm{M})$, piceatannol $(13.8 \mu \mathrm{M})$, herbacetin $(19.2 \mu \mathrm{M})$, baicalein $(20.3 \mu \mathrm{M})$, myricitrin $(21.7 \mu \mathrm{M})$, BITC $(4.5 \mu \mathrm{M})$, PEITC (14.2 $\mu \mathrm{M})$, and AITC (33.3 $\mu \mathrm{M})$ (Supplemental Fig. 2). Under the conditions, $\mathrm{IC}_{50} \mathrm{~s}$ of the positive controls, ebselen and GC376, were 0.4 and $18.8 \mu \mathrm{M}$, respectively. However, quercetin, pectolinarin, rutin, and cyanidine-3glucoside, in which their inhibitory activity to $\mathrm{M}^{\text {pro }}$ has already been reported [11-14], did not show suppressive effect at the concentration examined $(20 \mu \mathrm{M})$.

The changes in the mass of $\mathrm{M}^{\text {pro }}$ by incubation with the phytochemicals were examined. Because MBP-M ${ }^{\text {pro }}(77.5 \mathrm{kDa})$ signal by the intact MS was not clearly observed, MBP-cleaved $\mathrm{M}^{\text {pro }}$ (34.7 kDa) was prepared and used after that. The mass changes of the $\mathrm{M}^{\text {pro }}$ by phytochemical conjugation $(1 \mu \mathrm{M})$ were shown in Fig. 1B. One or two molecule(s) of piceatannol, myricetin, EGCG, and theaflavin were adducted onto the $\mathrm{M}^{\text {pro }}$. Herbacetin, baicalein, myricitrin, and ITCs showed significant inhibitory effects, but their covalent adducts were not observed at $1 \mu \mathrm{M}$ (Fig. 1B). The adductions by myricetin and EGCG $(0-5 \mu \mathrm{M})$ were dosedependently observed, and the enzyme activities were decreased accordingly (Fig. 2A).

Next, the adduction of EGCG and myricetin to the enzyme was confirmed by quinone staining. After the reaction of the $\mathrm{M}^{\text {pro }}$ enzyme with the two phytochemicals, the $\mathrm{M}^{\text {pro }}$ was subjected to gel electrophoresis, blotted onto a PVDF membrane, and then stained with NBT (Fig. 2B). From $0.625-\mu \mathrm{M}$ phytochemicals, NBT-reactive quinone moieties at the location of $\mathrm{M}^{\text {pro }}$ were observed dose-dependently. Simultaneously the free thiols in the $\mathrm{M}^{\text {pro }}$ were decreased by increasing the concentration of phytochemicals. Most of the enzyme activity was retained when reduced glutathione (GSH, $1 \mathrm{mM}$ ) was added to the buffer in advance (Fig. 3C). Additionally, the control enzyme activity was approximately increased 1.3-fold by GSH supplementation (data not shown). Quinone staining by EGCG/myricetin was also canceled when incubated in the presence of GSH.

The enzyme $(5 \mu \mathrm{M})$ was digested with chymotrypsin after incubation with EGCG or myricetin $(10 \mu \mathrm{M})$. The peptide digests were separated by HPLC and then analyzed by MS(/MS). If adducted, the mass of the peptide conjugated with EGCG or myricetin should increase by 456 or $316 \mathrm{Da}$, corresponding to the conjugation of EGCG (MW 458) or myricetin (MW 318). The presumed signals of EGCG adducted to NGSCGSVGF (25.9 min) and LNGSCGSVGF (27.6 min) were detected on the extract ion chromatograms (Fig. 3A(a)). Additionally, the sequence,
LNGSCGSVGF, is formed by one missed cleavage with chymotrypsin. Their sequences of the fragments induced by collision-induced dissociation were assigned as the peptides adducted by EGCG at the C (Cys) of the (L)NGSCGSVGF (Fig. 3A (c, e)) by comparing the prediction by the MS-Digest. The signals ( $-170 \mathrm{Da})$ from the EGCG-adducted sequences were also observed, and the mass difference was probably formed by liberating galloyl moiety at the D ring of EGCG [21]. This indicates that the thiol was covalently conjugated with the B ring of EGCG, but not the $\mathrm{D}$ ring. The myricetin-adducted peptides (+316 Da), corresponding to the NGSCGSVGF (30.1 $\mathrm{min}$ ) and LNGSCGSVGF (31.7 $\mathrm{min})$, were observed (Fig. 3B (b)), and the fragmentation patterns (Fig. 3B (d, f)) were matched with the predicted myricetin-adducted NGSCGSVGF and LNGSCGSVGF.

\section{Discussion}

The viral $\mathrm{M}^{\text {pro }}$ is a promising target for preventing the infection of coronavirus, i.e., the $\mathrm{M}^{\text {pro }}$ inhibitor GC376 could prevent viral infections $[1,22,23]$. Synthetic $\alpha$-ketoamide compounds inhibited the SARS-CoV-2 $\mathrm{M}^{\text {pro }}$, possibly by covalent adduction to Cys 145 of the enzyme [3,4]. A clinical candidate, PF-07321332, targeted to the enzyme has recently proceeded to Phase 1 trial [24]. Apart from medicine, various components in food could be beneficial to life. However, the boundary between medicine and food is ambiguous because some foods, such as herbs, are used as folk medicine. Indeed, as introduced, many phytochemicals prevent the recombinant viral enzyme in vitro. However, the mechanism of inhibiting phytochemicals is unknown in detail. Hence, our preliminary study indicated that some phytochemicals could not be applied to the FRET assay with a fluorescent plate reader because of its fluorescence quenching ability or self-fluorescence as supposed [15]. We then evaluated the enzyme activity by analyzing the cleaved fluoresce peptide after separation by conventional HPLC. A drawback of this assay is the run time for analysis, $10 \mathrm{~min} / \mathrm{sample}$. In contrast, chromatography separates the fluoresce peptide with a test chemical, avoiding the possible interference between them.

Of the chemicals tested, the inhibitory activities of some phytochemicals have already been examined at a $200-\mu \mathrm{M}$ concentration by FRET assay [25]. In contrast, current results using 37 compounds differ from the outcome in some points. It might be due to the difference in the evaluation method of enzyme activity. In this study, at $20 \mu \mathrm{M}$, myricetin, EGCG, theaflavin, and BITC considerably inhibited the viral protease, and to a lesser extent, piceatannol, PEITC, herbacetin, baicalein, myricitrin, and AITC. Furthermore, the patterns of inhibition and adduct formation were relatively matched (Fig. $1 \mathrm{AB}$ ). In addition, as mentioned before, most of these phytochemicals have been reported as possible inhibitors of $\mathrm{M}^{\text {pro }}$.

This study also focused on intact phytochemicals and their metabolites because ingested phytochemicals are often metabolized into conjugates, such as glucuronide or sulfate formed by intracellular phase II enzymes in cells. Possible inhibitory effects of these metabolites by a flavonoid have already been supposed by in silico study [26,27], and baicalin, a glucuronide of baicalein, inhibits SARS-CoV-2 recombinant $\mathrm{M}^{\text {pro }}$ in vitro [12]. However, most metabolites or the glucosides of flavonoids examined, except for myricitrin (a rhamnoside of myricetin), did not inhibit the enzyme at the concentration tested $(20 \mu \mathrm{M})$. Among the circulating metabolites, the glucuronides could be cleaved at the inflammatory site by a secreted $\beta$-glucuronidase and then regenerate aglycone $[28,29]$. The sulfate form of phytochemicals could restore the original phytochemical in cells [30]. These probably suggest that glucuronides or sulfates of phytochemicals, which are often abundantly present in blood compared with phytochemical (aglycone), are possibly converted to the active hydrophobic aglycone form and then incorporated into an infected cell.

When EGCG, myricetin, theaflavin, and piceatannol $(1 \mu \mathrm{M})$ were mixed with $0.5-\mu \mathrm{M}$ enzyme for $30 \mathrm{~min}$ at neutral $\mathrm{pH}$, the adduct was formed (Fig. 1B). A former study showed that EGCG might have pos- 

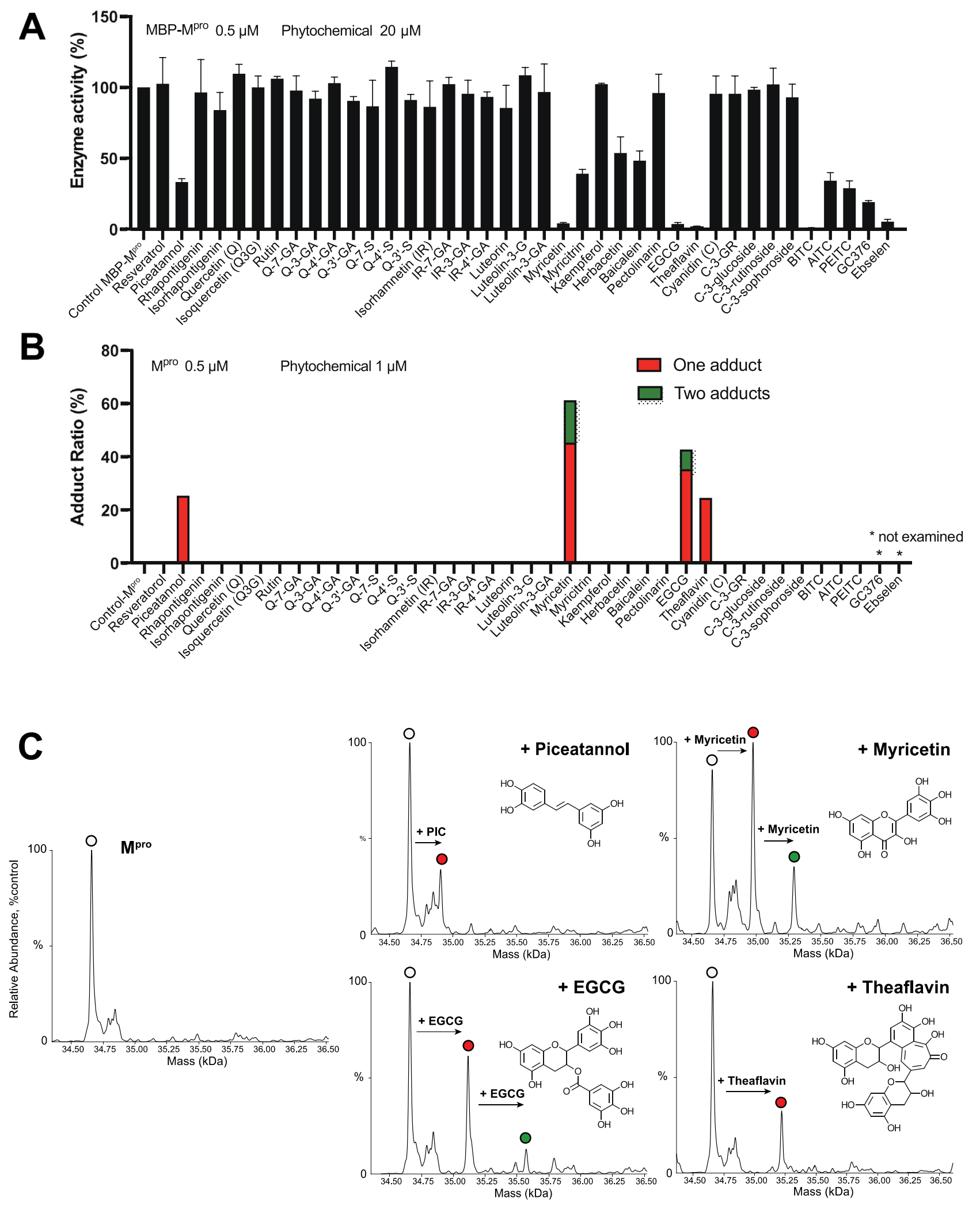

Fig. 1. The effect of various phytochemicals on the enzyme activity and its mass. (A) MBP-tagged $\mathrm{M}^{\text {pro }}(0.5 \mu \mathrm{M})$ was incubated with phytochemicals $(20 \mu \mathrm{M})$ at $37^{\circ} \mathrm{C}$ for $30 \mathrm{~min}$. After the reaction, a peptide substrate was added. The enzyme activity was then analyzed by measuring the cleaved fluoresce peptide generated from the substrate as described in Materials and Methods. (B) $\mathrm{M}^{\text {pro }}$ (MBP-removed, $0.5 \mu \mathrm{M}$ ) was incubated with the phytochemicals $(1 \mu \mathrm{M})$ at $37^{\circ} \mathrm{C}$ for $30 \mathrm{~min}$. After the reaction, changes in the mass of $\mathrm{M}^{\mathrm{pro}}$ were examined by intact MS. The deconvolution of the mass spectrum was performed using the UniDec software, and the mass shifts of the enzyme by the adduction of one or more phytochemicals were evaluated by measuring the respective peak area. The deconvoluted mass chromatograms of piceatannol, myricetin, EGCG, and theaflavin with the individual chemical structure are also shown. Abbreviations used: Q, quercetin; G, glucose; glucuronide, GA; S, sulfate; IR, isorhamnetin; EGCG, epigallocatechin gallate; C, cyanidine; GR, glucosyl-rutinoside; BICT, benzyl isothiocyanate; AITC, allyl isothiocyanate; PEITC, phenethyl isothiocyanate. 
A

\section{EGCG}
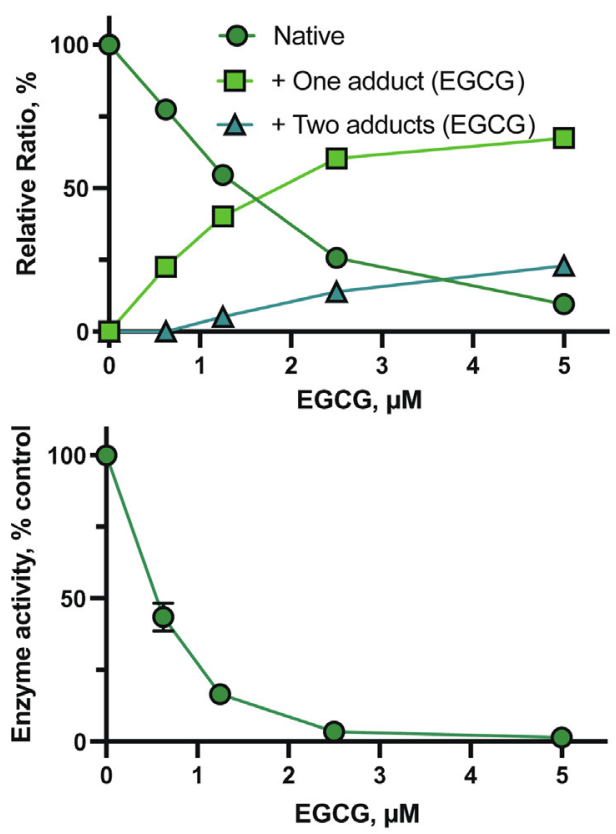

B

\section{EGCG}
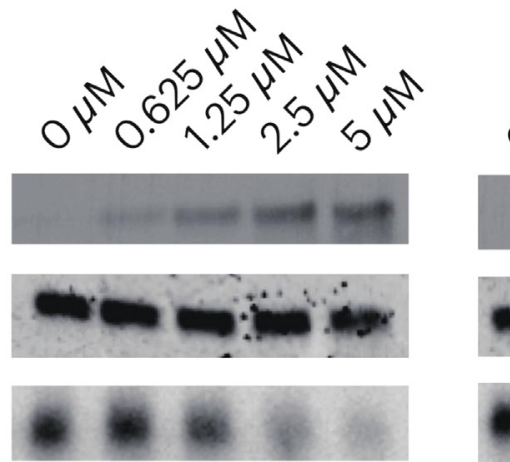

\section{Myricetin}
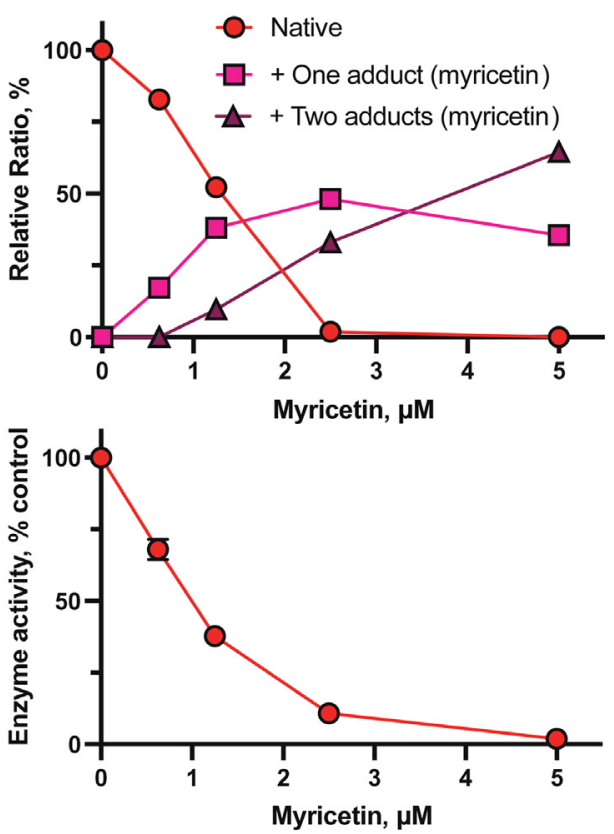

Myricetin

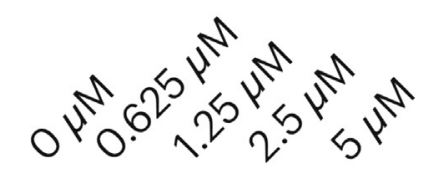

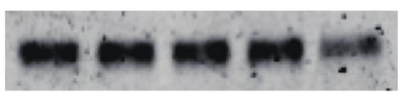

Protein Stain

\section{Thiol Stain \\ Thiolstain}

\section{Quinone Stain}

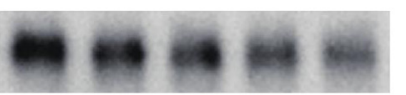

C
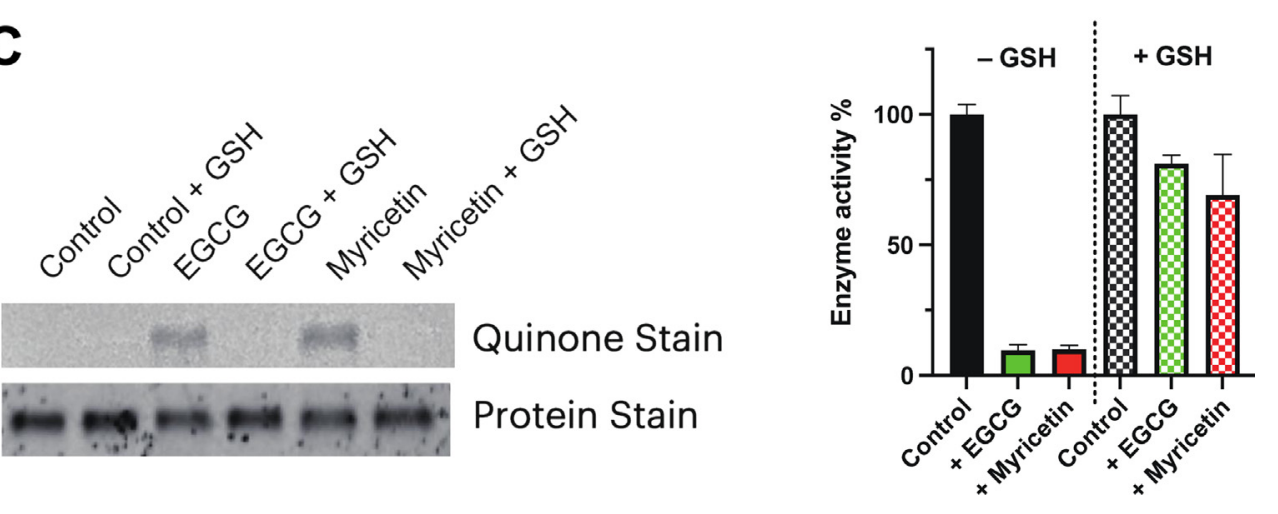

Fig. 2. Dose-dependent changes in the mass and activity of the enzyme incubated with EGCG or myricetin. (A) After incubating the $\mathrm{M}^{\text {pro }}$ enzyme $(0.5 \mu \mathrm{M})$ with $1-5-\mu \mathrm{M}$ myricetin/EGCG, adduct formation was estimated by intact MS. The dose-dependent effects of EGCG and myricetin on enzyme activity were also examined. The reaction of the enzyme with the substrate was set for $15 \mathrm{~min}$. (B) After incubation, the proteins were separated by SDS-PAGE. Gel/blot images for the enzyme exposed to EGCG or myricetin were shown. For protein staining, the gel was stained using Flamingo gel stain. Additionally, the gel was blotted onto a PVDF membrane for quinone staining and then stained using nitroblue tetrazolium (NBT) in alkaline glycinate buffer. The enzyme was first derivatized by iodoacetamide-LC-biotin and then applied to a gel and blotted for free thiol staining. The blotted membrane was incubated with streptavidin-peroxidase followed by adding a chemiluminescence reagent for evaluation. (C) The enzyme $(0.5 \mu \mathrm{M})$ was incubated with $2.5-\mu \mathrm{M}$ EGCG or myricetin in the presence or absence of 1-mM reduced glutathione (GSH) for $30 \mathrm{~min}$. For the control, DMSO (final 1\%) was used. The enzyme activity (\%) was expressed as \%control or \%control with GSH. The enzyme was also separated by SDS-PAGE and blotted onto the membrane. The membrane was then stained by NBT as described in (B). 

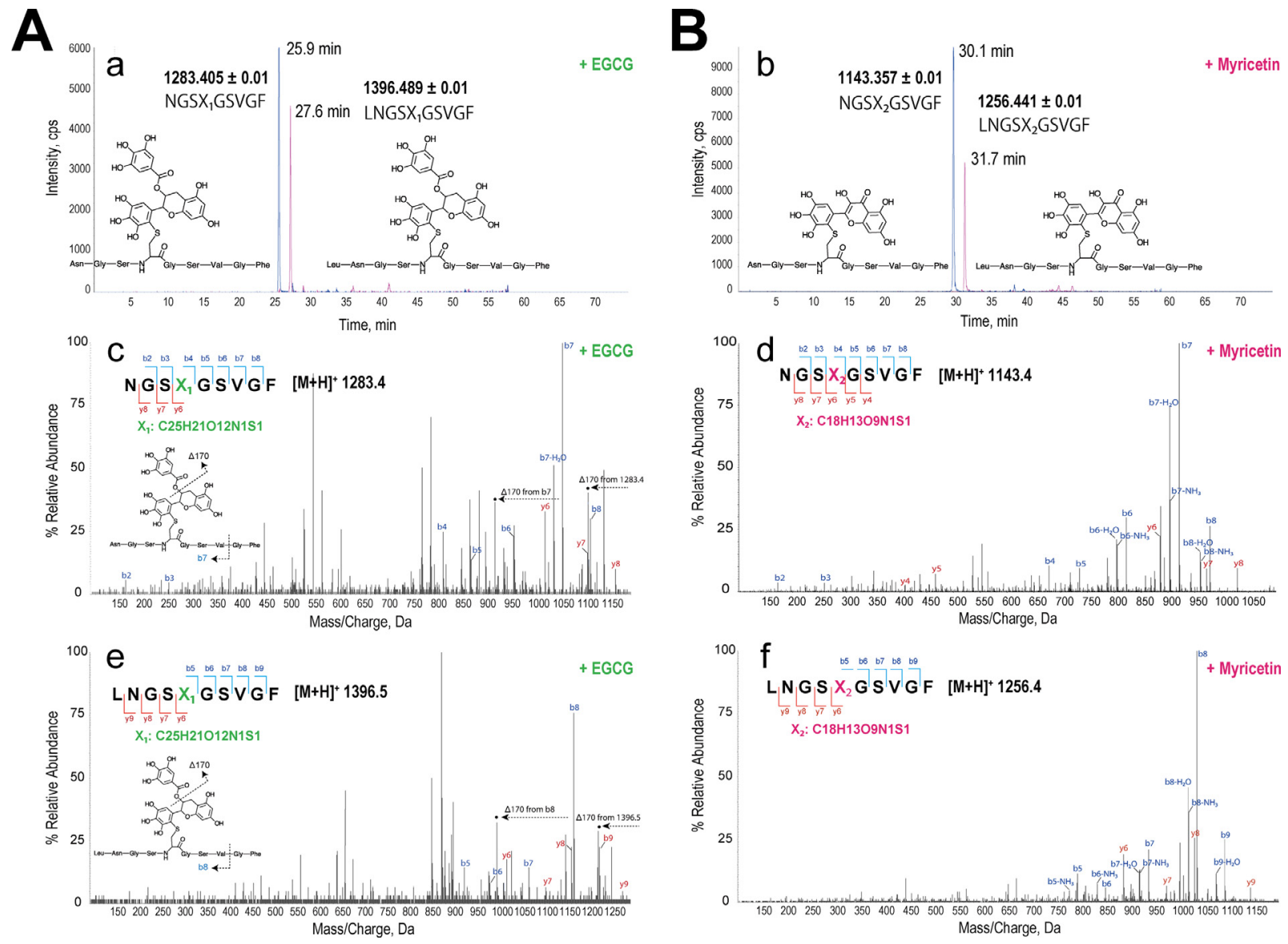

Fig. 3. MS(/MS) analysis of covalently modified peptides at the active site. A; EGCG. B; Myricetin. After incubation, $\mathrm{M}^{\text {pro }}$ was digested with chymotrypsin. Extract ion chromatograms of the theoretical mass of EGCG- or myricetin-conjugated peptides with proposed chemical structures (a, b). $\mathrm{X}_{1}$ indicates EGCG-conjugated cysteine, and $\mathrm{X}_{2}$ indicates myricetin-conjugated cysteine. $\mathrm{NGSX}_{1 / 2}$ GSVGF (1283.405 \pm 0.01 (EGCG), $1143.357 \pm 0.01$ (myricetin)) and LNGSX $1 / 2$ GSVGF (1396.489 \pm 0.01 (EGCG), $1256.441 \pm 0.01$ (myricetin)) were the theoretical chymotrypsin-cleavable sequences (possible conjugated peptides) located at the active site. The MS/MS chromatograms generated from NGSX ${ }_{1 / 2}$ GSVGF are shown in c (EGCG) and d (myricetin). Those of LNGSXGSVGF (1 missed cleavage) are shown in e (EGCG) and $\mathrm{f}$ (myricetin). Inset fragmentation schemes, c and e: EGCG-dependent characteristic fragments $(\Delta 170)$ from the liberation of the galloyl moiety at the D ring in EGCG by collision-induced dissociation of EGCG-adducted peptides.

sibly covalently modified a cysteinyl thiol residue of glyceraldehyde-3phosphate dehydrogenase and inactivated the enzyme at $37^{\circ} \mathrm{C}$ for 30 $\min$ [21]. We have also found that myricetin and EGCG inhibit the $\mathrm{M}^{\text {pro }}$ enzyme accompanying the formation of one or two molecules adducted to the enzyme molecule dose-dependently (Fig. 2). The autoxidation of catechin or flavonoid generates a quinone moiety. The formed quinone could react with a thiol of the enzyme, resulting in the enzyme conjugation with the phytochemical (Fig. 4) [31]. Piceatannol is abundantly present in the fruit of Passiflora edulis [32] and is a metabolite of resveratrol. In this study, we have discovered that piceatannol inhibits the enzyme; the catechol structure of piceatannol is presumably the critical structure for conjugation.

Pyrogallol (myricetin and its synthetic derivative) is considered an alternative warhead in the design of targeted covalent ligands [10]. EGCG has trihydroxy benzoyl moieties at the $\mathrm{B}$ and $\mathrm{D}$ rings. The liberation of the galloyl moiety $(\Delta 170)$ at the $\mathrm{D}$ ring was observed in fragments of digested peptides conjugated with EGCG (Fig. 3A (c, e)), and similar liberation of the galloyl moiety $(\Delta 170)$ from EGCG-adducted MHRQETVDC was already reported [21]. In contrast, a signal generated from the liberation of $\Delta 290$ from the opposite side (A, B, and C rings) was not observed (data not shown). Thus, this indicates that EGCG was mainly conjugated with a protein thiol via the galloyl moiety at the B ring. Additionally, by comparing myricetin with myricitrin, sugar moiety in the phytochemical weakens its inhibitory activity. Formerly, in a lipid oxidation system, myricetin and thiol conjugates were identified
[33]. Recently, the conjugation ( $\Delta 316 \mathrm{Da}$ ) of one molecule of myricetin to $\mathrm{M}^{\text {pro }}$ evaluated by intact MS has been reported [10], and the mechanism of conjugation of myricetin with protein thiol via the formation of $o$-quinone is also proposed.

Quinone staining showed that a reduced type of glutathione (GSH) suppressed the conjugation of EGCG/myricetin (Fig. 2C). Furthermore, enzyme activity loss by EGCG/myricetin was canceled in the presence of GSH. These results suggested that GSH reacted with the o-quinone moiety of the phytochemical instead of a thiol in the enzyme. Thus, quinones were probably reactants to the enzyme.

We attempted to identify EGCG or myricetin-adducted site in the enzyme by chymotrypsin digestion (Fig. 3). A former study showed that ebselen, PX-12, and carmofur adduct to Cys145, which was assigned by analyzing TIKGSFLNGSCGSVGF or FTIKGSFLNGSCGSVGF digest by chymotrypsin [3]. We have found that the EGCG/myricetin-adducted peptides ( 0 and 1 missed cleavage) are located at the active site of $\mathrm{M}^{\text {pro }}$, (L)NGSCGSVGF. Furthermore, this is the first report that phytochemicals covalently adduct the active site of $\mathrm{M}^{\text {pro }}$.

The inhibitors, ebselen, disulfiram, carmofur, PX-12, tideglusib and shikonin, were found to be nonspecific promiscuous SARS-CoV-2 main protease inhibitors because they lose their activities in the presence of a reducing reagent like dithiothreitol [34]. In contrast, ebselen and its derivative possess $\mathrm{M}^{\text {pro }}$ inhibitory and antiviral activities [35]. The favored reaction between quinone and an enzyme thiol may lead to offtarget effects; quinones of phytochemicals may be trapped by intravital 
<smiles>CCC(NCCSc1c(C2Oc3cc(O)cc(O)c3CC2OC(=O)c2cc(O)c(O)c(O)c2)cc(O)c(O)c1O)C(=O)CCCNc1ccccc1</smiles>

Fig. 4. Proposed reaction scheme for adduction of EGCG or myricetin with $\mathrm{M}^{\mathrm{pro}}$.<smiles>CCNC(CSc1oc2cc(O)cc(O)c2c(=O)c1-c1cc(O)c(O)c(O)c1O)C(CC)NCCc1ccccc1</smiles>

GSH, cysteine, or protein thiols before approaching the viral enzyme in infected cells. Then, a thiol-sensitive oxidized phytochemical may be classified as a nonspecific inhibitor of the $\mathrm{M}^{\text {pro }}$ enzyme. However, it has also been reported that the reaction rate of myricetin with GSH is slow [10]. Additionally, in vivo environment is more hypoxic (reductive) than in vitro test tubes. Furthermore, there are many causes of oxidation of phytochemicals in intra- and extracellular environments [36]; therefore, quinone form of phytochemicals could react with the viral thiol enzyme under higher oxidative stress.

The inhibitory effect of ITC including PEITC on $\mathrm{M}^{\text {pro }}$ has been reported $[37,38]$. This study also shows that three ITCs prevent cleaved peptide generation. As already known, ITC is highly reactive to thiols, forming a covalent ITC-thiol adduct. Therefore, the modification of cysteine at the active site by ITC would inactivate the enzyme. However, the adducts were not observed at least at 1- $\mu \mathrm{M}$ ITC (Fig. 1B), probably because the thiocarbamoyl linkage between ITC and thiol is unstable. ITC also reacts with amines to a lesser extent $[39,40]$. Therefore, the study on the effect of ITC on the enzyme remains unelucidated.

It has been reported that the plasma concentration of total polyphenol metabolites ranged from 0 to $4 \mu \mathrm{M}$ with an intake of 50-mg aglycone equivalents [41]. Therefore, it may not be enough to deliver these possible functional phytochemicals to infected cells. However, current results have shown that some phytochemicals at a physiological concentration, a few $\mu \mathrm{Ms}$, inhibit the viral enzyme in vitro. Furthermore, former studies have shown that cellular proteins were modified by $5-40-\mu \mathrm{M}$ catechins, including EGCG, supplemented to the culture medium [21,42], suggesting that EGCG (and other phytochemicals) could penetrate the cell and covalently modify cellular proteins. Besides, nanodelivery systems with food phytochemicals may also overcome the issue of lower bioavailability [43].

A limitation of this study is that the inhibition was tested by incubating the recombinant enzyme with pure phytochemicals in vitro. Therefore, using SARS-CoV-2-infected cells with a test compound [44] is preferable; however, it requires a higher biosafety, such as biosafety level-3 environment. Alternatively, a cell-based Flip-GFP and cell-based luciferase-Glo assays for $\mathrm{M}^{\text {pro }}$ have been developed [45-49]. These novel assay systems could validate the inhibitory effects of the phytochemicals.

Conclusively, we have estimated the inhibitory effect of the phytochemicals on the virus recombinant main protease by measuring the generation of the intact fluorescent-cleaved peptide substrate. It was found that some phytochemicals, including myricetin and EGCG, significantly inhibited the enzyme even at a physiological concentration.
Furthermore, the covalent phytochemical-Mpro adducts were observed along with the decrease in enzyme activity, and the adduction happened at the Cys of the active site of $\mathrm{M}^{\text {pro }}$. Finally, verifying in vivo occurrences of the reaction between phytochemicals and the viral enzyme should be a subject for future studies.

\section{Declaration of Competing Interest}

There is no conflict of interest.

\section{CRediT authorship contribution statement}

Yoji Kato: Conceptualization, Funding acquisition, Investigation, Methodology, Project administration, Supervision, Writing - original draft, Writing - review \& editing. Akari Higashiyama: Investigation, Writing - original draft. Emi Takaoka: Investigation, Writing - original draft. Miyu Nishikawa: Investigation, Writing - original draft. Shinichi Ikushiro: Investigation, Methodology, Supervision, Writing - review \& editing.

\section{Acknowledgments}

This work is partly supported by grants from the Ijima Memorial Foundation for the Promotion of Food Science and Technology. We are thankful to Motonori Tsuji (Institute of Molecular Function) for his preliminary in silico study and helpful advice. We are also grateful to Chisato Yakemoto and Professor Mikiko Ito for their contribution to a preliminary study.

\section{Supplementary materials}

Supplementary material associated with this article can be found, in the online version, at doi:10.1016/j.arres.2021.100021.

\section{References}

[1] Y. Kim, H. Liu, A.C. Galasiti Kankanamalage, S. Weerasekara, D.H. Hua, W.C. Groutas, K.O. Chang, N.C. Pedersen, Reversal of the progression of fatal coronavirus infection in cats by a broad-spectrum coronavirus protease Inhibitor, PLoS Pathog. 12 (2016) e1005531, doi:10.1371/journal.ppat.1005531.

[2] A.D. Rathnayake, J. Zheng, Y. Kim, K.D. Perera, S. Mackin, D.K. Meyerholz, M.M. Kashipathy, K.P. Battaile, S. Lovell, S. Perlman, W.C. Groutas, K.O. Chang, 3C-like protease inhibitors block coronavirus replication in vitro and improve survival in MERSCoV-infected mice, Sci. Transl. Med. 12 (2020), doi:10.1126/scitranslmed.abc5332. 
[3] Z. Jin, X. Du, Y. Xu, Y. Deng, M. Liu, Y. Zhao, B. Zhang, X. Li, L. Zhang, C. Peng, Y. Duan, J. Yu, L. Wang, K. Yang, F. Liu, R. Jiang, X. Yang, T. You, X. Liu, X. Yang, F. Bai, H. Liu, X. Liu, L.W. Guddat, W. Xu, G. Xiao, C. Oin, Z. Shi, H. Jiang, Z. Rao, $\mathrm{H}$. Yang, Structure of M(pro) from SARS-CoV-2 and discovery of its inhibitors, Nature 582 (2020) 289-293, doi:10.1038/s41586-020-2223-y,

[4] L. Zhang, D. Lin, X. Sun, U. Curth, C. Drosten, L. Sauerhering, S. Becker, K. Rox, R. Hilgenfeld, Crystal structure of SARS-CoV-2 main protease provides a basis for design of improved alpha-ketoamide inhibitors, Science 368 (2020) 409-412, doi:10.1126/science.abb3405.

[5] S. Jo, H. Kim, S. Kim, D.H. Shin, M.S. Kim, Characteristics of flavonoids as potent MERS-CoV 3C-like protease inhibitors, Chem. Biol. Drug Des. 94 (2019) 2023-2030, doi:10.1111/cbdd.13604

[6] S. Jo, S. Kim, D.H. Shin, M.S. Kim, Inhibition of SARS-CoV 3CL protease by flavonoids, J. Enzyme Inhib. Med. Chem. 35 (2020) 145-151, doi:10.1080/14756366.2019.1690480.

[7] Y.B. Ryu, H.J. Jeong, J.H. Kim, Y.M. Kim, J.Y. Park, D. Kim, T.T. Nguyen, S.J. Park, J.S. Chang, K.H. Park, M.C. Rho, W.S. Lee, Biflavonoids from Torreya nucifera displaying SARS-CoV 3CL(pro) inhibition, Bioorg. Med. Chem. 18 (2010) 7940-7947, doi:10.1016/j.bmc.2010.09.035.

[8] M. Jang, Y.I. Park, Y.E. Cha, R. Park, S. Namkoong, J.I. Lee, J. Park, Tea polyphenols EGCG and theaflavin inhibit the activity of SARS-CoV-2 3CLprotease in vitro, Evid. Based Complement Alternat. Med. 2020 (2020) 5630838, doi: $10.1155 / 2020 / 5630838$.

[9] W.C. Chiou, J.C. Chen, Y.T. Chen, J.M. Yang, L.H. Hwang, Y.S. Lyu, H.Y. Yang, C. Huang, The inhibitory effects of PGG and EGCG against the SARS-CoV-2 3C-like protease, Biochem. Biophys. Res. Commun. (2021), doi:10.1016/j.bbrc.2020.12.106.

[10] H. Su, S. Yao, W. Zhao, Y. Zhang, J. Liu, Q. Shao, Q. Wang, M. Li, H. Xie, W. Shang, C. Ke, L. Feng, X. Jiang, J. Shen, G. Xiao, H. Jiang, L. Zhang, Y. Ye, Y. Xu, Identification of pyrogallol as a warhead in design of covalent inhibitors for the SARSCoV-2 3CL protease, Nat. Commun. 12 (2021) 3623, doi:10.1038/s41467-02123751-3.

[11] O. Abian, D. Ortega-Alarcon, A. Jimenez-Alesanco, L. Ceballos-Laita, S. Vega, H.T. Reyburn, B. Rizzuti, A. Velazquez-Campoy, Structural stability of SARS-CoV2 3CLpro and identification of quercetin as an inhibitor by experimental screening, Int. J. Biol. Macromol. 164 (2020) 1693-1703, doi:10.1016/j.ijbiomac.2020.07.235.

[12] S. Jo, S. Kim, D.Y. Kim, M.S. Kim, D.H. Shin, Flavonoids with inhibitory activity against SARS-CoV-2 3CLpro, J. Enzyme Inhib. Med. Chem. 35 (2020) 1539-1544, doi:10.1080/14756366.2020.1801672.

[13] P. Deetanya, K. Hengphasatporn, P. Wilasluck, Y. Shigeta, T. Rungrotmongkol, K. Wangkanont, Interaction of 8-anilinonaphthalene-1-sulfonate with SARSCoV-2 main protease and its application as a fluorescent probe for inhibitor identification, Comput. Struct. Biotechnol. J. 19 (2021) 3364-3371, doi:10.1016/j.csbj.2021.05.053.

[14] E. Pitsillou, J. Liang, C. Karagiannis, K. Ververis, K.K. Darmawan, K. Ng, A. Hung, T.C. Karagiannis, Interaction of small molecules with the SARS-CoV-2 main protease in silico and in vitro validation of potential lead compounds using an enzyme-linked immunosorbent assay, Comput. Biol. Chem. 89 (2020) 107408, doi:10.1016/j.compbiolchem.2020.107408.

[15] P. Gribbon, A. Sewing, Fluorescence readouts in HTS: no gain without pain? Drug Discov. Today 8 (2003) 1035-1043, doi:10.1016/s1359-6446(03)02895-2.

[16] S. Tanaka, A. Trakooncharoenvit, M. Nishikawa, S. Ikushiro, H. Hara, Comprehensive analyses of quercetin conjugates by LC/MS/MS revealed that isorhamnetin-7- O-glucuronide-4'- O-sulfate Is a major metabolite in plasma of rats fed with quercetin glucosides, J. Agric. Food Chem. 67 (2019) 4240-4249, doi:10.1021/acs.jafc.8b06929.

[17] T. Nakamura, C. Kinjo, Y. Nakamura, Y. Kato, M. Nishikawa, M. Hamada, N. Nakajima, S. Ikushiro, K. Murota, Lymphatic metabolites of quercetin after intestinal administration of quercetin-3-glucoside and its aglycone in rats, Arch. Biochem. Biophys. 645 (2018) 126-136, doi:10.1016/j.abb.2018.03.024.

[18] M.T. Marty, A.J. Baldwin, E.G. Marklund, G.K. Hochberg, J.L. Benesch, C.V. Robinson, Bayesian deconvolution of mass and ion mobility spectra: from binary interactions to polydisperse ensembles, Anal. Chem. 87 (2015) 4370-4376, doi:10.1021/acs.analchem.5b00140.

[19] M.A. Paz, R. Flückiger, A. Boak, H.M. Kagan, P.M. Gallop, Specific detection of quinoproteins by redox-cycling staining, J. Biol. Chem. 266 (1991) 689692.

[20] Y. Kato, A.V. Peskin, N. Dickerhof, D.T. Harwood, A.J. Kettle, Myeloperoxidase catalyzes the conjugation of serotonin to thiols via free radicals and tryptamine-4,5-dione, Chem. Res. Toxicol. 25 (2012) 2322-2332, doi:10.1021/ tx300218f.

[21] T. Ishii, T. Mori, T. Tanaka, D. Mizuno, R. Yamaji, S. Kumazawa, T. Nakayama, M. Akagawa, Covalent modification of proteins by green tea polyphenol (-)epigallocatechin-3-gallate through autoxidation, Free Radic. Biol. Med. 45 (2008) 1384-1394, doi:10.1016/j.freeradbiomed.2008.07.023.

[22] C. Ma, M.D. Sacco, B. Hurst, J.A. Townsend, Y. Hu, T. Szeto, X. Zhang, B. Tarbet, M.T. Marty, Y. Chen, J. Wang, Boceprevir, GC-376, and calpain inhibitors II, XII inhibit SARS-CoV-2 viral replication by targeting the viral main protease, Cell Res. 30 (2020) 678-692, doi:10.1038/s41422-020-0356-z.

[23] W. Vuong, M.B. Khan, C. Fischer, E. Arutyunova, T. Lamer, J. Shields, H.A. Saffran, R.T. McKay, M.J. van Belkum, M.A. Joyce, H.S. Young, D.L. Tyrrell, J.C. Vederas, M.J. Lemieux, Feline coronavirus drug inhibits the main protease of SARS-CoV-2 and blocks virus replication, Nat. Commun. 11 (2020) 4282, doi:10.1038/s41467-020-18096-2.

[24] D.R. Owen, C.M.N. Allerton, A.S. Anderson, L. Aschenbrenner, M. Avery, S. Berritt, B. Boras, R.D. Cardin, A. Carlo, K.J. Coffman, A. Dantonio, L. Di, H. Eng, R. Ferre,
K.S. Gajiwala, S.A. Gibson, S.E. Greasley, B.L. Hurst, E.P. Kadar, A.S. Kalgutkar, J.C. Lee, J. Lee, W. Liu, S.W. Mason, S. Noell, J.J. Novak, R.S. Obach, K. Ogilvie, N.C. Patel, M. Pettersson, D.K. Rai, M.R. Reese, M.F. Sammons, J.G. Sathish, R.S.P. Singh, C.M. Steppan, A.E. Stewart, J.B. Tuttle, L. Updyke, P.R. Verhoest, L. Wei, Q. Yang, Y. Zhu, An oral SARS-CoV-2 $\mathrm{M}^{\text {pro }}$ inhibitor clinical candidate for the treatment of COVID-19, medRxiv (2021) (2021) 21261232 2007.2028, doi:10.1101/2021.07.28.21261232.

[25] T.T.H. Nguyen, J.-H. Jung, M.-K. Kim, S. Lim, J.-M. Choi, B. Chung, D.-W. Kim, D. Kim, The Inhibitory effects of plant derivate polyphenols on the main protease of SARS coronavirus 2 and their structure-activity relationship, Molecules 26 (2021) 1924, doi:10.3390/molecules26071924.

[26] F.M.A. da Silva, K.P.A. da Silva, L.P.M. de Oliveira, E.V. Costa, H.H. Koolen, M.L.B. Pinheiro, A.Q.L. de Souza, A.D.L. de Souza, Flavonoid glycosides and their putative human metabolites as potential inhibitors of the SARS-CoV-2 main protease (Mpro) and RNA-dependent RNA polymerase (RdRp), Mem. Inst. Oswaldo Cruz. 115 (2020) e200207, doi:10.1590/0074-02760200207.

[27] S.A. Cherrak, H. Merzouk, N. Mokhtari-Soulimane, Potential bioactive glycosylated flavonoids as SARS-CoV-2 main protease inhibitors: A molecular docking and simulation studies, PLoS One 15 (2020) e0240653, doi:10.1371/journal.pone. 0240653

[28] K. Shimoi, N. Saka, R. Nozawa, M. Sato, I. Amano, T. Nakayama, N. Kinae, Deglucuronidation of a flavonoid, luteolin monoglucuronide, during inflammation, Drug Metab. Dispos. 29 (2001) 1521-1524 doi.

[29] Y. Kawai, T. Nishikawa, Y. Shiba, S. Saito, K. Murota, N. Shibata, M. Kobayashi, M. Kanayama, K. Uchida, J. Terao, Macrophage as a target of quercetin glucuronides in human atherosclerotic arteries: implication in the anti-atherosclerotic mechanism of dietary flavonoids, J. Biol. Chem. 283 (2008) 9424-9434, doi:10.1074/jbc.M706571200.

[30] Y. Kato, M. Kawai, S. Kawai, Y. Okano, N. Rokkaku, A. Ishisaka, K. Murota, T. Nakamura, Y. Nakamura, S. Ikushiro, Dynamics of the cellular metabolism of leptosperin found in manuka honey, J. Agric. Food Chem. 67 (2019) 10853-10862, doi:10.1021/acs.jafc.9b03894.

[31] Y. Kato, N. Suga, Covalent adduction of endogenous and food-derived quinones to a protein: its biological significance, J. Clin. Biochem. Nutr. 62 (2018) 213-220, doi:10.3164/jcbn.18-26.

[32] Y. Matsui, K. Sugiyama, M. Kamei, T. Takahashi, T. Suzuki, Y. Katagata, T. Ito, Extract of passion fruit (Passiflora edulis) seed containing high amounts of piceatannol inhibits melanogenesis and promotes collagen synthesis, J. Agric. Food Chem. 58 (2010) 11112-11118, doi:10.1021/jf102650d.

[33] T. Masuda, Y. Miura, M. Inai, A. Masuda, Enhancing effect of a cysteinyl thiol on the antioxidant activity of flavonoids and identification of the antioxidative thiol adducts of myricetin, Biosci., Biotechnol. Biochem. 77 (2013) 1753-1758, doi:10.1271/bbb.130315.

[34] C. Ma, Y. Hu, J.A. Townsend, P.I. Lagarias, M.T. Marty, A. Kolocouris, J. Wang, Disulfiram Ebselen, Carmofur, PX-12, Tideglusib, and Shikonin are nonspecific promiscuous SARS-CoV-2 main protease inhibitors, ACS Pharmacol. Translat. Sci. 3 (2020) 1265-1277, doi:10.1021/acsptsci.0c00130.

[35] K. Amporndanai, X. Meng, W. Shang, Z. Jin, M. Rogers, Y. Zhao, Z. Rao, Z.J. Liu, H. Yang, L. Zhang, P.M. O'Neill, S. Samar Hasnain, Inhibition mechanism of SARSCoV-2 main protease by ebselen and its derivatives, Nat. Commun. 12 (2021) 3061, doi:10.1038/s41467-021-23313-7.

[36] J.L. Bolton, T. Dunlap, Formation and biological targets of quinones: cytotoxic versus cytoprotective effects, Chem. Res. Toxicol. 30 (2017) 13-37, doi:10.1021/acs.chemrestox.6b00256.

[37] L. Peñalver, P. Schmid, D. Szamosvári, S. Schildknecht, C. Globisch, K. Sawade, C. Peter, T. Böttcher, A Ligand Selection Strategy Identifies Chemical Probes Targeting the Proteases of SARS-CoV-2, Angew. Chem. Int. Ed. 60 (2021) 6799-6806, doi:10.1002/anie.202016113.

[38] M. Kuzikov, E. Costanzi, J. Reinshagen, F. Esposito, L. Vangeel, M. Wolf, B. Ellinger, C. Claussen, G. Geisslinger, A. Corona, D. Iaconis, C. Talarico, C. Manelfi, R. Cannalire, G. Rossetti, J. Gossen, S. Albani, F. Musiani, K. Herzog, Y. Ye, B. Giabbai, N. Demitri, D. Jochmans, S.D. Jonghe, J. Rymenants, V. Summa, E. Tramontano, A.R. Beccari, P. Leyssen, P. Storici, J. Neyts, P. Gribbon, A. Zaliani, Identification of inhibitors of SARS-CoV-2 3CL-Pro enzymatic activity using a small molecule in vitro repurposing screen, ACS Pharmacol. Transl. Sci. 4 (2021) 10961110, doi:10.1021/acsptsci.0c00216.

[39] T. Nakamura, Y. Kawai, N. Kitamoto, T. Osawa, Y. Kato, Covalent modification of lysine residues by allyl isothiocyanate in physiological conditions: plausible transformation of isothiocyanate from thiol to amine, Chem. Res. Toxicol. 22 (2009) 536-542, doi:10.1021/tx8003906.

[40] T. Nakamura, M. Hirakawa, Y. Nakamura, A. Ishisaka, N. Kitamoto, A. Murakami, Y. Kato, Covalent modification of phosphatidylethanolamine by benzyl isothiocyanate and the resultant generation of ethanolamine adduct as its metabolite, Chem. Res. Toxicol. 32 (2019) 638-644, doi:10.1021/acs.chemrestox. 8b00331.

[41] C. Manach, G. Williamson, C. Morand, A. Scalbert, C. Remesy, Bioavailability and bioefficacy of polyphenols in humans. I. Review of 97 bioavailability studies, Am. J. Clin. Nutr. 81 (2005) 230S-242S, doi:10.1093/ajcn/81.1.230S.

[42] T. Tanaka, T. Ishii, D. Mizuno, T. Mori, R. Yamaji, Y. Nakamura, S. Kumazawa, T. Nakayama, M. Akagawa, (-)-Epigallocatechin-3-gallate suppresses growth of AZ521 human gastric cancer cells by targeting the DEAD-box RNA helicase p68, Free Radic. Biol. Med. 50 (2011) 1324-1335, doi:10.1016/j.freeradbiomed.2011. 01.024.

[43] W. Dai, C. Ruan, Y. Zhang, J. Wang, J. Han, Z. Shao, Y. Sun, J. Liang, Bioavailability enhancement of EGCG by structural modification and nano-delivery: A review, J. Funct. Foods 65 (2020) 103732, doi:10.1016/j.jff.2019.103732. 
[44] S.-i. Hattori, N. Higashi-Kuwata, H. Hayashi, S.R. Allu, J. Raghavaiah, H. Bulut, D. Das, B.J. Anson, E.K. Lendy, Y. Takamatsu, N. Takamune, N. Kishimoto, K. Murayama, K. Hasegawa, M. Li, D.A. Davis, E.N. Kodama, R. Yarchoan, A. Wlodawer, S. Misumi, A.D. Mesecar, A.K. Ghosh, H. Mitsuya, A small molecule compound with an indole moiety inhibits the main protease of SARS-CoV-2 and blocks virus replication, Nat. Commun. 12 (2021) 668, doi:10.1038/s41467-021-20900-6.

[45] Z. Xia, M. Sacco, Y. Hu, C. Ma, X. Meng, F. Zhang, T. Szeto, Y. Xiang, Y. Chen, J. Wang, Rational Design of Hybrid SARS-CoV-2 main protease inhibitors guided by the superimposed cocrystal structures with the peptidomimetic inhibitors GC376, Telaprevir, and Boceprevir, ACS Pharmacol. Translat. Sci. 4 (2021) 1408-1421, doi:10.1021/acsptsci.1c00099.

[46] H.A. Rothan, T.C. Teoh, Cell-based high-throughput screening protocol for discovering antiviral inhibitors against SARS-COV-2 main protease (3CLpro), Mol. Biotechnol. 63 (2021) 240-248, doi:10.1007/s12033-021-00299-7.
[47] J.M.O. Rawson, A. Duchon, O.A. Nikolaitchik, V.K. Pathak, W.S. Hu, Development of a cell-based luciferase complementation assay for identification of SARS-CoV-2 3CL(pro) Inhibitors, Viruses 13 (2021), doi:10.3390/v13020173.

[48] C. Ma, H. Tan, J. Choza, Y. Wang, J. Wang, Validation and invalidation of SARS-CoV-2 main protease inhibitors using the Flip-GFP and Protease-Glo luciferase assays, bioRxiv (2021) 458041 2021.2008.2028, doi:10.1101/2021.08.28. 458041.

[49] P.P. Gerber, L.M. Duncan, E.J. Greenwood, S. Marelli, A. Naamati, A. TeixeiraSilva, T.W. Crozier, I. Gabaev, J.R. Zhan, T.E. Mulroney, E.C. Horner, R. Doffinger, A.E. Willis, J.E. Thaventhiran, A.V. Protasio, N.J. Matheson, A proteaseactivatable luminescent biosensor and reporter cell line for authentic SARS-CoV2 infection, bioRxiv (2021) 435957 2021.2003.2022, doi:10.1101/2021.03.22. 435957. 